\title{
El tratamiento antirretroviral temprano se asoció a una mayor sobrevida en pacientes con VIH
}

\author{
Early antiretroviral therapy was associated with better survival for HIV patients
}

Kitahata N y col. NEJM 2009;360(18):1815-26

\section{Objetivo}

Comparar la sobrevida de los pacientes sometidos a tratamiento antirretroviral temprano (TAT) o diferido (TAD) según su valor inicial de recuento de CD4.

\section{Diseño, Lugar y Pacientes}

Estudio observacional de cohortes realizado en Canadá y Estados Unidos. Fueron seguidos por diez años 17.517 pacientes con VIH sin tratamiento antirretroviral previo ni enfermedades marcadoras de SIDA.

\section{Intervención}

Se llevaron a cabo dos análisis: el primer grupo $(\mathrm{N}=8.362)$ incluyó pacientes con recuentos de CD4 entre 350 y 500, de los cuales el $25 \%$ (2.084) recibió TAT (dentro de los primeros seis meses a la medición de sus CD4), y el 75\% (6.278) recibió TAD (cuando sus CD4 descendieron a menos de 350$)$. El segundo grupo $(\mathrm{N}=9.155)$ eran pacientes con recuentos de CD4 mayores a 500, de los cuales el $24 \%$ (2.220) recibió TAT y el 76\% (6.935) recibió TAD (ante CD4 menores a 500).

\section{Medición de resultados principales}

El resultado principal fue muerte por cualquier. Se ajusto* por sexo, edad y recuento basal de CD4. También se analizaron coinfección con hepatitis $\mathrm{C}(\mathrm{HCV})$, antecedentes de drogadicción endovenosa (DEV) y valor de carga viral.

\section{Resultados principales}

La tasa de mortalidad en los grupos sometidos a TAT fue de 1,6 por cada 100 personas/año* en el grupo CD4 350 a 500, y de 1,3 en el grupo con CD4 >500. No se reporto la tasa cruda de los grupos sometidos a TAD debido a existencia de datos censurados*. EI TAD se asoció significativamente a un mayor riesgo de muerte en ambos grupos (ver Tabla 1).

Tabla 1: Riesgo de muerte asociado al tratamiento antirretroviral diferido según el nivel de CD4

\begin{tabular}{c|c|c} 
& $\begin{array}{c}\text { CD4 350 a 500 } \\
\text { RR (IC95\%) }\end{array}$ & $\begin{array}{c}\text { CD4 }>\mathbf{5 0 0} \\
\text { RR (IC95\%) }\end{array}$ \\
\hline Sin ajustar por carga viral & $1,69(1,26$ a 2,26) & $1,94(1,37$ a 2,79$)$ \\
\hline Ajustando por carga viral & $1,63(1,21$ a 2,19) & $1,85(1,20$ a 2,86$)$ \\
\hline Ajustando por edad & $1,68 £(1,48$ a 1,91$)$ & $1,83(1,62$ a 2,06$)$ \\
\hline Ajustando por antecedentes de DEV & $1,28(0,85$ a 1,93) & $1,73(1,08$ a 2,78$)$ \\
\hline Ajustando por coinfección con HCV & $1,71(1,20$ a 2,45$)$ & $2,03(1,37$ a 3,01$)$ \\
\hline
\end{tabular}

RR: Riesgo Relativo. DEV: drogadicción endovenosa. HCV: Hepatitis C. IC95\%: intervalo de confianza del $95 \%$. £ Por cada 10 años más.

\section{Conclusiones}

EI TAT se asoció a una mayor sobrevida en relación al TAD.

Palabras claves: VIH, tratamiento antirretroviral.

Keywords: HIV, antiretroviral treatment.
Fuentes de financiamiento: North American AIDS Cohort Collaboration on
Research and Design (NA-ACCORD) of the International Epidemiological Databases to Evaluate AIDS project.

Fuentes de financiamiento: National Institute of Health

\section{Comentario}

Las recomendaciones actuales sostienen el inicio del tratamiento antirretroviral ante valores de CD4 por debajo de 350 (independientemente de la carga viral del paciente), o ante recuentos de CD4 por arriba de este valor en caso de enfermedad marcadora de SIDA, nefropatía asociada a VIH o coinfección con HBV, entre otros. Sin embargo la fuerza de esta recomendación es menor para aquellos pacientes sin estas comorbilidades y con recuentos de CD4 mayores a 350'.

Uno de los puntos más cuestionados del presente trabajo fue el no revelar las tasas brutas de muerte en los pacientes del grupo sometido a TAD, planteando directamente los valores relativos ${ }^{2}$ Por otro lado al no estar adecuadamente balanceados los grupos $y$, habiendo un mayor porcentaje de pacientes con antecedentes de DEV y HCV en el grupo de TAD, es entendible que aumente la mortalidad en este grupo. Sin embargo, los valores que muestran los autores como resultados principales del estudio no son los ajustados por DEV y coinfección por HCV, dos factores pronósticos importantísimos que al ser incluidos cambian los resultados de manera significativa, al menos en el primer caso, en el grupo con
CD4 350-500 (ver Tabla). Por último, como en cualquier estudio observacional (y a pesar de los ajustes realizados) podrían haber otros factores confunidores* no evaluados que conduzcan a resultados sesgados. Por ejemplo se puede suponer que los pacientes del grupo TAT son más adherentes, cumplen mejor el tratamiento o tienen mejor pronostico, y esto puede afectar significativamente los resultados (similar al sesgo de voluntario sano* observado en muchos estudios).

\section{Conclusión del comentador}

Se sabe que un estudio observacional no representa la mejor metodología para sacar conclusiones definitivas sobre terapéutica. Por lo tanto el presente trabajo no tiene el peso suficiente como para cambiar las recomendaciones actuales. Sin embargo, sus conclusiones aportan como impulsoras de nuevos estudios aleatorizados que contesten esta importante pregunta, como los que están siendo actualmente conducidos en distintas partes del mundo, incluido la Argentina.

Ver glosario*

Yamila De Vas y Federico Augustovski [ Servicio de Medicina Familiar y Comunitaria del Hospital Italiano de Buenos Aires yamila.devas@ hospitalitaliano.org.a ]

Recibido el 06/04/2010 y aceptado el 05/05/2010

De Vas Y, Augustovski F. El tratamiento temprano se asoció a una mayor sobrevida en pacientes con VIH. Evid Actual Práct Ambul 13(3):88 JulSet 2010. Comentado de: Kitahata MM, y cols. Effect of early versus deferred antiretroviral therapy for HIV on survival. N Engl J Med. 2009;360(18):1815-26. Epub 2009 Apr 1. PMID: 19339714

\section{Referencias}

1. Panel on Antiretroviral Guidelines for Adults and Adolescents. Guidelines for the use of antiretroviral agents in HIV-1-infected adults and adolescents (en linea). Department of Health and Human Services. December 1, 2009; 1-161. Disponible en: http://www.aidsinfo.nih.gov/ContentFiles/AdultandAdolescentGL.pdf (último acceso 02/08/2010). 2. Buchbinder, SP et all. Early versus Deferred Antiretroviral Therapy for HIV. NEJM 2009 361: 822-824 